\title{
İnme Hastalarında Çift Yönlü Görev Aktivitesinin Etkinliği
}

\author{
The Efficacy of Dual Task Activity In Stroke Patients
}

Derya Tuba BAL, Tuba Tülay KOCA, Ejder BERK, Burhan Fatih KOÇYİĞíT, Vedat NACİTARHAN

Kahramanmaraş Sütçü İmam Üniversitesi, Tip Fakültesi, Fiziksel Tip ve Rehabilitasyon Anabilim Dal, Kahramanmaraş, Türkiye

Geliş tarihi: 04.06.2020 Kabul tarihi: 26.06.2020 DOI: 10.17517/ksutfd.726160

\section{Özet}

Amaç: İnmeli hastalarda çift yönlü görev aktivitesinin fonksiyon ve yaşam kalitesi üzerine etkisini araştırmak.

Gereç ve Yöntemler: Çalışmaya 20 yaş üzeri kırk $(n=40)$ inmeli hasta dahil edildi. Çalışma grubu ve kontrol grubu olarak belirlendi. Grup 1 (n:20) hastalara konvansiyonel egzersiz tedavisi (statik, dinamik denge egzersizleri ve yürüme eğitimi) 4 haftalık 45 şser dakika verilirken grup 2'deki (n:20) hastalara konvansiyonel egzersiz ile eş zamanlı; sözel akıcılık ve matematik problemleri uygulandı. Hastaların demografik verileri kaydedildi ve rehabilitasyon programına başlamadan önce ve 4 haftalık rehabilitasyon programını aldıktan sonra 6 dakika yürüme testi, fonksiyonel ambulasyon skala (FAS), Rivermead mobilite indeksi, mini mental test, inmeye özgü yaşam kalitesi ölçeği, Ulusal Sağlık İnme Enstitüsü Skalası (NIHSS) skoru ile değerlendirildi.

Bulgular: Çalışma grubundaki hastaların (grup 2) tedavi sonrasında; üst ( $p<0.01)$, el ( $p<0.01)$, alt ( $p<0.01)$ ekstremite Brunnstrom evrelendirmesinde, stroke yaşam kalitesinde $(\mathrm{p}<0.01)$, FAS ( $\mathrm{p}=0.02)$, Rivermead mobilite indeksi ( $\mathrm{p}<0.01), 6 \mathrm{dk}$ yürüme mesafesi $(\mathrm{p}<0.01)$ ve mini mental testte $(\mathrm{p}=0.01)$ istatistiksel olarak anlamlı iyileşme gözlemlenmiştir. Kontrol (grup 1$)$ grubunda ise tedavi sonrasında; üst $(\mathrm{p}=0.01)$, el $(0.01)$, alt ekstremite $(\mathrm{p}<0.01)$ Brunnstrom evrelendirmesinde, stroke yaşam kalitesinde ( $p=0.01)$, Rivermead mobilite indeksi $(p<0.01), 6$ dk yürüme mesafesi $(p<0.01)$ ve mini mental testte ( $p=0.04)$ istatistiksel olarak anlamlı farklılık gözlemlenmiştir. Çalışma ve kontrol grubu tedavi protokolü öncesi ve sonrası tüm parametreler kendi arasında karşılaştırıldığında benzer sonuçlar elde edildi. Buna göre tedavi öncesi fonksiyonel ve yaşam kalitesini gösteren parametreler her iki grupta benzerdi. Tedavi programı sonrası da her iki grup sonuçları benzer bulundu.

Sonuç: Çift yönlü görev egzersizinin inmeli hastalarda fonksiyonel düzey, yaşam kalitesi ve mental duruma olumlu etkisi olup, konvansiyonel tedavilere üstünlügü yoktur. İnmeli hastalarda nörorehabilitasyonda tercih edilebilir.

Anahtar sözcükler: İnme, Çift yönlü görev, Rehabilitasyon 


\section{Abstract}

Objective: To investigate the effect of dual task activity on function and quality of life in stroke patients.

Material and Methods: 20 years and older fourty $(n=40)$ stroke patients were included in the study. Group 1 (n:20) patients were given conventional exercise therapy (static, dynamic balance exercises and gait training) 45 minutes a week for 4 weeks. Group 2 (n: 20) patients were given conventional exercise and verbal fluency and mathematics problems were applied concurrently. The demographic data of the patients were recorded and 6-minute walk test, functional ambulatory scale (FAS), Rivermead mobility index, mini-mental test, stroke-specific quality of life scale, National Institutes of Health Stroke Scale (NIHSS) was evaluated before and after 4 weeks of rehabilitation program.

Results: There was statistically significant difference in the study group (group 2); after rehabilitation; upper ( $<<0.01$ ), hand $(\mathrm{p}<0.01)$, lower $(\mathrm{p}<0.01)$ extremity Brunnstrom staging, stroke quality of life $(\mathrm{p}<0.01)$, FAS $(\mathrm{p}=0.02)$, Rivermead mobility index $(\mathrm{p}<0.01), 6$ min walking distance $(\mathrm{p}<0.01)$ and mini mental test $(\mathrm{p}<0.01)$. In the control group after rehabilitation; there was statistically significant difference in upper $(\mathrm{p}=0.01)$, hand $(\mathrm{p}=0.01)$, lower $(\mathrm{p}<0.01)$ extremity Brunnstrom staging, stroke quality of life $(\mathrm{p}=0.01)$, NIHSS $(\mathrm{p}=0.01)$, Rivermead mobility index $(\mathrm{p}<0.01), 6$ min walking distance $(\mathrm{p}<0.01)$ and minimental test $(\mathrm{p}=0.04)$. In the study and control groups all parameters compared before and after the treatment and results were similar. Results of both groups were similar after the treatment program.

Conclusion: Dual task exercise has a positive effect on functional level, quality of life and mental status in stroke patients and has no superiority over conventional treatments. It may be preferred for neurorehabilitation in stroke patients.

Key words: Stroke, Dual task, Rehabilitation

Yazışma Adresi: Tuba Tülay Koca Kahramanmaraş Sütçü İmam Üniversitesi, Tip Fakültesi, Fiziksel Tip ve Rehabilitasyon Anabilim Dalı,

Kahramanmaraş, Türkiye, Telefon: +90 5063819295 e-mail: tuba_baglan@yahoo.com ORCID No (Sırasılyla): 0000-0002-1963-8368,

0000-0002-4596-858, 0000-0002-0816-0960, 0000-0002-6065-8002, 0000-0003-1756-8615 


\section{GİRIŞ}

İnme; Dünya Sağlık Örgütü (DSÖ) tarafından 'vasküler kaynaktan başka görünen nedeni olmayan, 24 saatten uzun süren veya ölüme yol açan, hızlı gelişen, fokal beyin hasarı semptomu ve bulguları ile karakterize bir tablo' olarak bilinen ve kontrol edilebilen risk faktörlerine sahip, engellenebilir bir hastalık olarak tanımlanmıştır (1). İnme, risk faktörleri kontrol altına alındıktan sonra akut bakımdaki yoğun çabalar sonrasında Amerika Birleşik Devletleri`ndeki en yaygın beşinci ölüm sıralamasına inmiştir (2). İnsidans yaşla ilişkili olup 50 yaşından önce nadir iken 55 yaşından itibaren her dekatta iki katına çıkar, ancak 85 yaș üstü kadınlarda daha sık karşımıza çıkar (3).

Çift yönlü görev egzersizi iki ya da daha fazla kognitif ve motor aktivitenin aynı anda yapılabilmesidir (4). Nörofizyolojik bir işlemdir. İki görev aynı anda yapılırken dikkat kapasitesi etkin şekilde kullanılarak, görevlerin zorluğuna ve önceliğine göre dikkat paylaştırılması esasına dayanmaktadır. Zorluk miktarı arttıkça veya dikkat kapasitesi azaldıkça görevlerden biri ya da ikisinin de uygulanmasında eksiklikler ortaya çıkacaktır (5). İnme geçirenlerin hemen hemen üçte ikisinde yürüme ve mobilite disfonksiyonu vardır. Hastaların çoğunluğu inme sonrası 6 aylık dönemde nihayetinde bağımsız dolaşma şansına sahip iken yaklaşık \%30’u bunu başaramaz (6).

İnmeli hastaların tedavisinde amaç, genel olarak, en yüksek yaşam kalitesi ile mümkün olduğunca bağımsız yaşamalarını sağlamaktır. İnmeli hasta için optimal tedavi, inmenin türüne ve yaşam kalitesine olan etkisine bağlıdır. İlk olarak bozulmuş fonksiyonların yeniden işlevsel hale getirilmesi amaçlanırken, ayrıca inme sonrası karşımıza çıkan bir takım komplikasyonların tedavisini ve olası komplikasyonların önlenmesine yönelik tüm önlemlerin alınması da rehabilitasyon programının ana amaçlarından biridir. Kronik inmeli hastaların egzersiz programına denge ve/veya ağırlık aktarmayı içeren yürüyüş eğitimlerinin başarılı olduğunu gösteren çalışmaların yanında; kronik inmeli hastalarda ikili göreve dayalı egzersiz programının yürüme yeteneğini arttırmada uygulanabilir ve faydalı olduğunu destekleyen yayınlarbunmaktadır(4-8).

Literatüre baktığımızda; daha çok çift yönlü görev esnasında denge ve yürüme parametrelerindeki değişiklikleri değerlendiren çalışmalar mevcut. Bizim çalışmamızda çift yönlü görev egzersiz eğitimi alan inmeli hastalar tedavi sonrasında fonksiyonel ve yaşam kalitesi parametreleri incelenerek değerlendirildi. Hastaların fonksiyonel ve yaşam kalitelerini artıracak egzersiz protokolü oluşturmayı planladık ve bu amaçla inmeli hastalara rehabilitasyon programına çift yönlü görev egzersiz programını ekledik.

\section{GEREÇ VE YÖNTEMLER}

Çalışmamıza Fiziksel Tıp ve Rehabilitasyon Anabilim Dalı'nda yatarak veya ayaktan tedavi gören 40 inmeli hasta dahil edildi. Hastaların tanısı bilgisayarlı tomografi (BT) ve/veya manyetik rezonans görüntülüme (MRG) teknikleri ile doğrulanmıştı. Olgular benzer yaş, cinsiyet, VKİ, inme süresi ve türü açısından benzer 20>şerli iki gruba ayrıldı. Grup 1 inmeli 20 hasta; grup 2, 20 inmeli hastadan oluşturuldu. Tüm vakaların demografik verileri kaydedildi.

Rehabilitasyon programına başlamadan önce ve en az 4 haftalık rehabilitasyon programını aldıktan sonra motor ve fonksiyonel gelişimi değerlendirmek için üst ekstremite, el ve alt ekstremite Brunnstrom Evrelendirmesi; Rivermead mobilite indeksi, Ulusal Sağlık İnme Enstitüsü Skalası (NIHSS), inmeye özgü yaşam kalitesi ölçeği, Fonksiyonel ambulasyon skalası (FAS), 6 dakika yürüme testi kullanılarak değerlendirildi. Grup 1'de bulunan 20 inmeli hastaya 4 haftalık 45 şer dakika konvansiyonel egzersiz [aktif- pasif eklem hareket açıklığı (EHA) egzersizleri, denge ve yürüme eğitimi] verildi. Grup 2'ye konvansiyonel egzersizler (aktif- pasif EHA egzersizleri, denge ve yürüme eğitimi) esnasında sözel akıc1lık ve matematik problemleri uygulandı. Çalışma için klinik araştırmalar lokal etik kurul onayı alındı (Tarih: 29/05/2019; protokol no: 157). Tüm katılımcilardan onam formu alındı. Çalışma Helsinki Deklerasyon prensiplerine uygun yapıldı.

\section{Çalışmaya dahil edilme kriterleri:}

1. 20-65 yaş arası inmeli hastalar (65 yaş üzeri motor fonksiyonların osteoartrit nedeniyle etkilenebilmesi, bulguların ileri osteoartritten mi inmeden mi kaynaklandığ 1 ayrımı yapmayı zorlaştırması sebebiyle çalışmaya dahil edilmedi.)

2. Araştırmaya rıza gösteren inmeli hastalar

3. Fonksiyonel ambulasyon skala (FAS) evre 1,2,3,4

\section{Çalışmadan dışlama kriterleri:}

1. Propriyosepsiyon duyusu bozukluğuna sebep olabilecek hastalıklara sahip olmak (diyabetik polinöropati, kronik alkolizm, vb...)

2. Görme bozukluğu olanlar

3. Ciddi psikiyatrik veya kognitif problem nedeniyle koopere olamayan hastalar

4. Fonksiyonel ambulasyon skalası (FAS) evre 0 veya 5

5.Ağır kalp yetmezliği gibi sistemik problemi olan hastalar 6.Eşlik eden ciddi ortopedik problem olması

7. Bilateral tutulum

\section{İnmeye Özgü Yaşam Kalitesi Ölçeği}

1999 yılında Williams ve ark. tarafından geliştirilmiştir. Toplam 49 maddeden oluşan orijinal ölçek, mobilite, enerji, üst ekstremite fonksiyonu, kendine bakım, meslek/üretkenlik, mizaç, sosyal rol, ailenin rolü, vizyon, dil, düşünme, kişilik özelliklerini değerlendiren 12 alandan oluşmaktadır (9).

\section{Fonksiyonel Ambulasyon Skalası (FAS)}

Hastaların ambulasyon yeteneğini değerlendiren bir skaladır. 0 ile 5 arasında derecelendirilen altı kategoriye ayrılır: 
FAS 0: ambulasyon yok, FAS 1-2: bir kişi desteği olmadan yürüyemez, FAS 3-5: kendi kendine 6 metre yürüyebilir (10).

\section{Rivermead Mobilite İndeksi (RM)}

Mobilite durumunu değerlendirmek için kullanılan bir indekstir. Guttman Skalasına uyan 14 soru ve bir gözlemden oluşan, mobilizasyon özelliklerini içeren aktiviteleri sorgulamaktadır (11).

\section{Brunnstrom Motor Evrelemesi}

Motor fonksiyonlardaki iyileşmeyi değerlendirmek için kullanılır. En düşük evre (flask evre ve istemli hareket yok), evre 1'dir ve en yüksek evre ise (izole eklem hareketlerinin olduğu dönem) evre 6'dır (12).

\section{Ulusal Sağlık İnme Enstitüsü Skalası (NIHSS)}

Amerikan Ulusal Sağlık Enstitüsü tarafından derlenen klinik çalışmalarda kullanılabilecek ayrıntılı bir ölçektir. Ölçek; inmenin şiddetini ve inme sonrası prognozu objektif olarak değerlendirmeye yardımcı olmaktadır. NIHSS’te alınan puanın çok olması inme sonrası klinik durumun daha kötü olduğu anlamına gelir (13-15).

\section{Mini Mental Test}

Kısa bir eğitim almış hekim, hemşire ve psikologlarca 10 dakika gibi bir süre içinde, poliklinik koşulları ya da yatak başında uygulanabilir bir testtir (16).

\section{Dakika Yürüme Testi (6DYT)}

Amerikan Thoraks Topluluğu (ATS) tarafından Cooper ve ark. 1960'ta geliştirdikleri 12 dakika Cooper testinden uyarlanmış bir testtir. 6DYT, sağlıklı veya sağlıksız bireylerde kolayca uygulanabilen, egzersiz kapasitesi ve yürüme kapasitesinin yanı sıra kardiyovasküler birçok hastalığın göstergesi olarak değerlendirilen submaksimal bir test olarak tanımlanmaktadır (17).

\section{Propriyosepsiyon Ölçümü}

Baş parmak lokalizasyon testi (Thumb Localization Test) ve parmak kaydırma testi (finger shift test= up or down test) ile değerlendirildi (7).

\section{Uygulanan Rehabilitasyon Protokollerinin Tanıtımı}

Konvansiyonel egzersiz [Eklem hareket açıklığı (EHA) egzersizleri, denge ve yürüme egzersizleri] protokolü

İnmeli hastalara EHA egzersizleri ve etkilenmiş taraf üst ve alt ekstremite pasif ve aktif EHA egzersizleri uygulandiktan sonra; statik, dinamik denge egzersizleri ve yürüme eğitimi verildi. Statik denge egzersizleri için; gözler açık ve kapalı sert zeminde ayaklar omuz hizasında açık ve ayaklar bitişik tandem pozisyonda ayakta 30sn durma, tek ayak üstünde 15sn durma, gözler açık ve kapalı sünger zeminde ayaklar omuz hizasında açık ve ayaklar bitişik pozisyonda 30 sn ayakta durma, gözler açık ve kapalı, sert zeminde ve sünger zeminde ayaklar omuz hizasında açık ve ayaklar bitişik pozisyonda öne arkaya 10 tekrarlı ağırlık aktarma, gözler açık ve kapalı ayaklar omuz hizasında açık, ayaklar bitişik pozisyondayken fizyoterapistin dengeyi bozucu etkilerine karşı pozisyonunu 30sn devam ettirme aktiviteleri yaptırıldı. Dinamik denge egzersizlerinde kişilere; sandalyeye arka arkaya 5 defa oturup kalkma, 10 metre mesafeyi ileri-geri-yanlara doğru gözler açık yürüme aktiviteleri yaptırıldı.

\section{Kognitif egzersiz protokolii}

Hastalara sözel akıcılık ve matematik problemleri uygulandı. Sözel akıcılık aktiviteleri olarak sözcükleri tersten söyleme, zıt anlamlı kelimeler söyleme, seçilen harften itibaren geri veya ileri harfleri sayma, seçilen harfle başlayan sözcükleri bulma ve belli bir sınıftaki (Eşya, kadın ismi vb.) sözcükleri türetme aktiviteleri yaptırıldı. Matematik problemleri olarak kişilere basit toplama çıkarma işlemleri soruldu.

\section{İstatistiksel Analiz}

Analiz, SPSS 22 istatistik paketi kullanılarak yapılmıştır (Windows için IBM SPSS, sürüm 22, IBM Corporation, Armonk, New York, ABD). Sürekli veriler ortalama \pm standart sapma, kategorik değişkenler ise yüzde olarak özetlendi. Normal dağılımın değerlendirilmesinde Kolmogorov Smirnov testi kullanıldı. Normal dağılımlı sayısal veriler ortalama ve standard sapma olarak; normal dağılıma uymayanlar ortanca ve minimum/maksimum değerler olarak verildi. Kategorik değişkenler için McNemar testi, normal dağılımlı sürekli değiş̧kenler için eşleştirilmiş t testi ve dağılım çarp1tıldığında Wilcoxon işaret testi kullanılarak karşılaştırmalar yapıldı. Bağımsız gruplar arası değişkenler için Mann Whitney $U$ test veya independent samples $t$ test ile değerlendirildi. $\mathrm{P}<0.05$ değeri istatistiksel olarak anlamlı kabul edildi. Yapılan power analizi sonucunda iki grup ortalaması arasında 0.05 birimlik farkın anlamlı bulunabilmesi için her grupta gerekli minimum denek sayısı 20 olarak belirlenmiştir. Tip 1 hata payı $=0.01$, testin gücü: 0.08 .

\section{BULGULAR}

Grup 1 ortalama 55.5×13.9 yıl yaş ortalamasında 20 (7’si kadın/13'ü erkek) inme hastasından oluşmakta idi. İnme süresi ortancası 9.5 ay (minimum 1- maksimum 36 ay) idi. İnme türü 14'̈̈ (\%70) iskemik, 6’sı hemorajik (\%30) inme idi. Vücut kitle indeksleri ortalaması $27.5 \pm 5.1 \mathrm{~kg} / \mathrm{m}^{2}$ idi.

Grup $249.4 \pm 17.1$ yaş ortalamasında 20 (9’u kadın/ 11‘i erkek) inme hastasından oluşmakta idi. İnme süresi ortancası 3 ay (minimum 1 ay- maksimum 48 ay), inme türü 14 'ü (\%70) iskemik, 6’sı hemorajik (\%30) inme idi. Vücut kitle indeksleri ortalaması $27.5 \pm 5.1 \mathrm{~kg} / \mathrm{m}^{2}$ idi. Buna göre tanımlayıc1 veriler her iki grupta da benzerdi. Gruplara ait demografik veriler Tablo 1'de özetlenmektedir.

Grup 1 hastalar; tedavi öncesi ve sonrası üst, el ve alt ekstremite Brunnstromm evrelendirmesi, fonksiyonel am- 
bulasyon sınıflaması (FAS), stroke yaşam kalitesi, Rivermead Mobilite testi, NIHSS, 6 dk yürüme ve minimental test kullanılarak karşılaștırıldı (Tablo 2).

Buna göre tedavi sonrasında; üst ( $\mathrm{p}=0.01)$, el ( $\mathrm{p}=0.01)$, alt $(\mathrm{p}<0.01)$ ekstremite Brunstromm evrelendirmesinde, stroke yaşam kalitesinde $(\mathrm{p}=0.01)$, Rivermead mobilite indeksi $(\mathrm{p}<0.01), 6 \mathrm{dk}$ yürüme mesafesi $(\mathrm{p}<0.01)$ ve minimental testte $(\mathrm{p}=0.04)$ istatistiksel olarak anlamlı iyileşme gözlemlenmiştir. Hastaların FAS düzeylerinde istatistiksel olarak anlamlı iyileşme saptanmamıştır ( $\mathrm{p}=0.09)$.

Tablo 3'de Grup 2'de tedavi öncesi ve sonrasi parametrelerin karşılaştırılması verildi. Buna göre hastaların tedavi sonrasinda; üst $(\mathrm{p}<0.01)$, el $(\mathrm{p}<0.01)$, alt $(\mathrm{p}<0.01)$ ekstremite Brunnstrom evrelendirmesinde, stroke yaşam kalite- si $(\mathrm{p}<0.01)$, fonksiyonel ambulasyon sinıflandırması (FAS) $(\mathrm{p}=0.02)$, Rivermead mobilite indeksi $(\mathrm{p}<0.01), 6 \mathrm{dk}$ yürüme mesafesi $(p<0.01)$ ve mini mental testte $(p=0.01)$ istatistiksel olarak anlamlı iyileşme gözlemlenmiștir $(p<0.05)$. Hastaların NIHSS skorlarında istatistiksel olarak anlamlı iyileşme saptanmamıştır ( $\mathrm{p}=0.45)$.

Grup 1 ve Grup 2 tedavi protokolü öncesi ve sonrası tüm parametreler karşılaştırıldığında benzer sonuçlar elde edildi. Tablo 4'de özetlenmektedir. Buna göre tedavi öncesi fonksiyonel ve yaşam kalitesini gösteren parametreler her iki grupta benzerdi. Tedavi sonrası da her iki grup sonuçları benzer bulundu. Buna göre iki yöntemin birbirine üstünlükleri yoktur, benzer etkinliktedir.

Tablo 1. Her iki gruba ait tanımlayıcı verilerin karşılaştırılması

\begin{tabular}{|c|c|c|c|}
\hline & $\begin{array}{l}\text { Grup } 1(\mathrm{~N}=20) \\
\text { mean } \pm \text { std/median } \\
(\min -\mathrm{max}) / \%\end{array}$ & $\begin{array}{l}\text { Grup } 2(N=20) \\
\text { mean } \pm \text { std/median } \\
(\min -\max ) / \%\end{array}$ & $\mathbf{P}$ \\
\hline Yaş (yıl) & $55.5 \pm 13.9$ & $49.4 \pm 17.1$ & 0.22 \\
\hline Cinsiyet (K/E) & $7(\% 35) / 13(\% 65)$ & $9(\% 45) / 11(\% 55)$ & 0.47 \\
\hline VKİ $\left(\mathbf{k g} / \mathbf{m}^{2}\right)$ & $27.5 \pm 5.1$ & $27.5 \pm 5.1$ & 1.00 \\
\hline İnme süresi (ay) & 9.5 (1-36 ay) & $3(1-48)$ & 0.53 \\
\hline $\begin{array}{l}\text { İnme türü } \\
\text { İskemik } \\
\text { Hemorajik }\end{array}$ & $\begin{array}{l}14(\% 70) \\
6(\% 30)\end{array}$ & $\begin{array}{l}14(\% 70) \\
6(\% 30)\end{array}$ & 0.56 \\
\hline
\end{tabular}

Tablo 2. Grup 1'de tedavi öncesi ve sonrası parametrelerin karşılaştırılması

\begin{tabular}{|c|c|c|c|}
\hline & $\begin{array}{l}\text { Tedavi öncesi } \\
\text { mean } \pm \text { std/median } \\
(\min -\mathbf{m a x})\end{array}$ & $\begin{array}{l}\text { Tedavi sonrası } \\
\text { mean } \pm \text { std/median } \\
(\min -\max )\end{array}$ & $\mathbf{P}$ \\
\hline $\begin{array}{l}\text { Üst ekstremite } \\
\text { Brunnstromm }\end{array}$ & $3.5(1-6)$ & $4(2-6)$ & 0.01 \\
\hline El Brunnstromm* & $3(1-6)$ & $4(1-6)$ & 0.01 \\
\hline $\begin{array}{l}\text { Alt ekstremite } \\
\text { Brunnstromm }{ }^{\star}\end{array}$ & $4.5(2-6)$ & $5(3-6)$ & $<0.01$ \\
\hline FAS evreleri & $3(1-4)$ & $4(1-5)$ & 0.09 \\
\hline İnme yaşam kalitesi * & $121.8 \pm 37.5$ & $155.6 \pm 42$ & $<0.01$ \\
\hline NIHSS $^{*}$ & $4 \pm 2.7$ & $2.7 \pm 2.2$ & 0.01 \\
\hline Rivermead mobilite testi ${ }^{*}$ & $7.2 \pm 3.1$ & $9.1 \pm 4.1$ & $<0.01$ \\
\hline 6 dakika yürüme & $108.6 \pm 91.4$ & $157.8 \pm 125.1$ & $<0.01$ \\
\hline Minimental test $^{*}$ & $19 \pm 5.3$ & $21 \pm 4.3$ & 0.04 \\
\hline
\end{tabular}




\begin{tabular}{|c|c|c|c|}
\hline & $\begin{array}{l}\text { Tedavi öncesi } \\
\text { mean } \pm \text { std/median } \\
(\min -\max )\end{array}$ & $\begin{array}{l}\text { Tedavi sonrası } \\
\text { mean } \pm \text { std/median } \\
(\text { min-max })\end{array}$ & $\mathbf{P}$ \\
\hline Üst ekstremite Brunnstrom* & $3.5(1-6)$ & $4(2-6)$ & $<0.01$ \\
\hline El Brunnstrom* & $3(1-6)$ & $4(1-6)$ & $<0.01$ \\
\hline Alt ekstremite Brunnstrom ${ }^{\star}$ & $4.5(2-6)$ & $5(3-6)$ & $<0.01$ \\
\hline FAS evrelemesi & $3(1-3)$ & $4(1-5)$ & 0.02 \\
\hline Stroke yaşam kalitesi * & $121.8 \pm 37.5$ & $155.6 \pm 42$ & $<0.01$ \\
\hline NIHSS skor & $4 \pm 2.7$ & $2.7 \pm 2.2$ & 0.45 \\
\hline Rivermead * & $7.2 \pm 3.1$ & $9.1 \pm 4.1$ & $<0.01$ \\
\hline 6 dakika yürüme ${ }^{\star}$ & $108.6 \pm 91.4$ & $157.8 \pm 93.6$ & $<0.01$ \\
\hline Mini mental test * & $19 \pm 5.3$ & $21.4 \pm 4.3$ & $<0.01$ \\
\hline
\end{tabular}

\section{Tablo 4. Her iki grupta tüm parametrelerin tedavi öncesi ve sonrası karşılaştırılması (Mann Whitney -U testi)}

\begin{tabular}{|l|l|}
\hline & $\mathbf{P}$ \\
\hline Üst ekstremite Brunnstrom tedavi öncesi & 0.314 \\
\hline Üst ekstremite Brunnstrom tedavi sonrası & 0.327 \\
\hline El Brunnstrom tedavi öncesi & 0.369 \\
\hline El Brunnstrom tedavi sonrası & 0.620 \\
\hline Alt ekstremite Brunnstrom tedavi öncesi & 0.277 \\
\hline Alt ekstremite Brunnstrom tedavi sonrası & 0.183 \\
\hline FAS tedavi öncesi & 0.478 \\
\hline FAS tedavi sonrası & 0.149 \\
\hline Stroke yaşam kalitesi tedavi öncesi & 0.221 \\
\hline Stroke yaşam kalitesi tedavi sonrası & 0.429 \\
\hline NIHSS tedavi öncesi & 0.817 \\
\hline NIHSS tedavi sonrası & 0.778 \\
\hline Rivermead tedavi öncesi & 0.792 \\
\hline Rivermead tedavi sonrası & 0.380 \\
\hline 6 dakika yürüme testi tedavi öncesi & 0.414 \\
\hline 6 dakika yürüme testi tedavi sonrası & 0.253 \\
\hline Minimental test tedavi öncesi & 0.820 \\
\hline Minimental test tedavi sonrası & 0.799 \\
\hline Kisaltmalar: FAS: Fonksiyonel ambulasyon sınılaması. NIHSS: Ulusal Sağlı İnme Enstitüsü Skalası ${ }^{*}$ istatistiksel olarak anlamlı farklllık, p<0.05 \\
\hline
\end{tabular}

\section{TARTIŞMA}

Çift yönlü görev egzersizi, günlük yaşam aktivitelerinin çoğunun büyük bir bölümünü oluşturur; gerçek hayatta, insanların sadece denge ve hareketlilik becerilerini korumakla kalmayıp aynı zamanda diğer bilişsel veya motor görevleri de yerine getirmeleri gerekir. Geleneksel müdahaleler hastaları günlük yaşam aktivitelerinin çoğunun zorluklarıyla yeterince yüzleşmeye hazırlayamayacağından çift yönlü görev egzersizine olan ilgi artmaktadır. Bunlar genellikle eşzamanlı bilişsel ve motor görevleri içerirler (4-11). Farklı nörolojik ve romatizmal hastalıklarda araştırılmıştır, ancak inmeli kişiler için sınırlı sayıda literatür verisi mevcuttur.

Park JH ve ark., 21 hemiplejik hastaya günlük 30 dakika, haftada 5 gün, 3 hafta boyunca çift çift yönlü görev egzersizi uygulamış; egzersiz öncesi ve sonrasında Box ve blok testi, Kore-Modifiye Barthel İndeksi kullanılarak üst ekstremite fonksiyonundaki değişiklikler ölçülmüş. Sonuçta çift yönlü görev egzersizi uygulanan kronik inmeli hastalarda üst ekstremite fonksiyonunu ve günlük aktivitelerin performansında etkili bir şekilde iyileşme olduğunu göstermişler. Bizim 
çalışmamızda da çift yönlü görev egzersizi uygulanan ve uygulanmayan hastalarda üst, el, alt ekstremite Brunnstrom evrelendirmesinde, stroke yaşam kalitesinde, Rivermead mobilite indeksi, 6 dakika yürüme mesafesi ve mini mental testte istatistiksel olarak anlamlı iyileşme gözlemlenmiştir (18).

Pan $\mathrm{X}$ ve ark., erken rehabilitasyon tedavisinin akut inmeli hemiplejik hastaların alt ekstremite hareket kabiliyeti üzerindeki etkinliğinin araştırılması üzerine bir çalışma yapmıştır (19). Çalışmaya 86 akut inme olan hasta alınmış, kontrol grubundaki hastalara rutin primer tedavi uygulanırken, araştırma grubundaki hastalara temel tedaviye dayalı rehabilitasyon uygulanmış. Hemiplejik ekstremite Fugl-Meyer (FMA), nörolojik açıklık ölçeği (NDS) ve Barthel indeksi (BI) ölçekleri kullanılarak tedavi öncesi ve sonrası değerlendirilmiş. Tedaviden sonra, araştırma grubunda FMA, NDS ve BI dereceleri kontrol grubundakilere kıyasla belirgin şekilde daha üstün gelmiş ve farklar istatistiksel olarak anlamlı bulunmuş. Bu çalışma erken rehabilitasyon programına başlamanın iyileşmeyi olumlu yönde etkilediği ve rehabilitasyon programlarına akut bir şekilde başlanması gerektiğini gözler önüne seren bir çalışmadır. Bizim çalışmamızda da tüm dönem hastaları tedaviyi alan grubu oluşturmakta ve her iki grupta tedavi sonrasında üst, el ve alt ekstremite Brunnstrom evrelendirmesinde, stroke yaşam kalitesinde, NIHSS skor, Rivermead mobilite indeksi, 6 dakika yürüme mesafesi ve mini mental testte istatistiksel olarak anlamlı iyileşme gözlendi.

Günde 1 saat, haftada 3 gün, 12 hafta güçlendirme, fleksibilite ve aerobik egzersiz yapan yaşlı kimselerle, bu egzersizleri yaptığı esnada kelime bulma ve matematik işlemleri gibi bilişsel aktiviteler yapan yaşlı kimselerin bilişsel fonksiyonlarının karşılaştırmasında, eş zamanlı kognitif aktivite yapan bireylerde daha fazla kognitif gelişme görülmüş (20). Bizim çalışmamızda da konservatif tedavi ile çift yönlü görev egzersizi yapan hasta popülasyonunda mini mental test değerlerine kıyasla daha fazla iyileşme göstermiştir.

Nascimento ve ark. ise haftada 2 defa 60 dakika aerobik endurans, kuvvetlendirme, koordinasyon ve denge aktivitelerini içeren fiziksel egzersizin tek görev ve çift görev yürüme hızını arttırdığını ifade etmiştir. Bizim çalışmamızda da her iki grupta 6 dakika yürüme testinde aldıkları mesafe artmıştır. Bu durum egzersizin her koşulda yürüme mesafesini artırdığını desteklemektedir (21).

Yang YR ve ark.minimum yürüyüş hızı, 58 cm/s olan kronik inmeli hastalarda çift yönlü görev egzersizinin yürüme yeteneği üzerine etkinliğini araştıran bir çalışma yapmışlar. Katılımcılar kontrol ve deney grubu olarak ayrılmış. Deney grubundaki hastalara 4 haftalık top egzersiz programı uygulanırken kontrol grubu rehabilitasyon eğitimi almamış. Tek görev ve tepsi taşıma görevi sırasında yürüyüş performansı yürüme hızı, kadans, adım uzunluğu ve zamansal simetri indeksi ölçülmüş. Deney grubu, temporal hariç, seçilen tüm yürüme ölçümlerinde anlamlı iyileşme göstermişken kontrol grubunda değişiklik olmamış. Bu çalışma kronik in- meli hastalarda çift yönlü görev aktivitesine dayalı egzersiz programının yürüme yeteneğini arttırmada uygulanabilir ve faydalı olduğunu desteklemektedir (22). Bizim çalışmamızda da konvansiyonel egzersiz ve çift yönlü görev egzersizi yapan hasta gruplarında; üst, el, alt ekstremite Brunnstrom evrelendirmesinde, stroke yaşam kalitesinde FAS, Rivermead mobilite indeksi, 6 dakika yürüme mesafesi ve mini mental testte istatistiksel olarak anlamlı iyileşme gözlenmiştir. Bunun yanında konvansiyonel egzersiz alan hastalarda da üst, el, alt ekstremite Brunnstrom evrelendirmesinde, stroke yaşam kalitesinde NIHSS skor, Rivermead mobilite indeksi, 6 dakika yürüme mesafesi ve mini mental testte istatistiksel olarak anlamlı iyileşme gözlenmiştir ve iki egzersiz arasında anlamlı fark gözlenmemiştir. Çalışmaların gösterdiği üzere inmeli hastalarda egzersiz her dönemde yürüme performansinı artırmaktadır.

Liu Y ve ark. yaptığ yönlü görev yürüme eğitiminin inmeli hastalarda yürüme performansı üzerine etkilerini araştırmış. Katılımcılar ( $\mathrm{n}=$ 28), bilişsel çift yönlü görev yürüyüş eğitimi (CDTT) (n = 9), motor çift yönlü görev yürüyüş eğitimi (MDTT) $(n=9)$, ve geleneksel fizik tedavi (CPT) $(\mathrm{n}=10)$, grubu olarak ayrilmış. Hastalar yürürken ve motor görev yaparken, tek yürüme ve bilişsel görev yürüme (seri çıkarma) yaparken (tepsi taşırken) üç test ile değerlendirilmişler. Parametreler arasında yürüme hızı, kadans, adım süresi ve adım uzunluğu ile cDTT grubundaki katılımcıların, bilişsel-motor çift yönlü görev yürüyüş performansı (adım uzunluğu ve DTC hızı) iyileştiği saptanmış. MDTT grubundaki katılımcıların, motor çift görev yürüyüş performansı iyileşmiş. CDTT VE MDTT grubundaki performanslar arasında anlamlı fark bulunamamış (23). Bizim de çalışmamızda kognitif çift yönlü görev aktivite egzersizleri ile hastalar çalıştırıldı ve yürüme mesafelerinde istatistiksel olarak anlamlı bir iyileşme gözlemlendi.

Elhinidi E ve ark infantil hemiparezili hastalarda çift yönlü görev aktivite eğitiminin postural stabilite üzerine etkisini araştıran bir çalışma yapmışlar. 30 hastayı kontrol ve çalışma grupları olarak randomize ayırmışlar. Her iki gruba konvansiyonel egzersizler (denge egzersizleri, yürüyüş eğitimi ve hareket egzersizleri) uygulanmış ve çalışma grubuna ek olarak denge ve bilişsel aktiviteler içeren seçili çift yönlü görev aktivite eğitimi verilmiş. Egzersiz eğitimi haftanın üç günü altı hafta boyunca verilmiş ve hastalar Biodex Balance Sistemi ile değerlendirilmiş. Eğitimin sonunda her iki grupta da anlamlı bir düzelme varmış; ancak bu iyileşme çalışma grubunda anlamlı olarak daha fazla bulunmuş (24). Ancak bizim çalışmamızda ikili görev çift yönlü görev aktivitesi eğitimi alan ve konvansiyonel egzersiz uygulanan hastalarda anlamlı iyileşme olmakla beraber eğitim programının birbirlerine üstünlüğü saptanmamıştır.

Hanneke ve ark. yaptığı bir araştırmada; kronik inmeli hastalarda egzersiz tedavisinin denge kapasitesi üzerindeki etkilerini inceleyen araştırmalardan bir derleme yapmışlar. Hastalara denge, ağırlık aktarma, yoğun aerobik egzersizlerle yürüyüş içeren egzersizler uygulanmış. Meta-analize göre 
egzersiz alan inmeli hastalarda Berg Denge Ölçeği (28 çalışma, $\mathrm{n}=985)$, Fonksiyonel Erişim Testi (5 çalışma, $\mathrm{n}=153$ ), Duyusal Organizasyon Testi ( 4 çalışma, $\mathrm{n}=173$ ) ve ortalama postural salınım hızında ( 3 çalışma, $n=89$ ) anlamlı iyileşme saptanmış. Sonuç olarak kronik inmeli hastaların egzersiz programına denge ve/veya ağırlık aktarmayı içeren yürüyüş eğitimlerinin başarılı olduğu gösterilmiş (25).

Park MO ve ark. inmeli hastalarda farklı bilişsel görevlerin etkisini inceleyen bir çalışma yapmışlar. 30 inmeli hasta çift yönlü görev aktivite eğitimi alan $(\mathrm{n}=15)$ ve konvansiyonel eğitim alan ( $n=15)$ grup olarak 2'ye ayrılmış. Eğitim haftanın 3 günü her seans 30 dakika olacak şekilde 6 hafta boyunca uygulanmış. çift yönlü görev aktivite eğitimi alan grupta Berg Denge Ölçeği anlamlı olarak iyileşmiş olarak değerlendirilmiş. Sonuç olarak bilişsel görevlerin kullanıldığg çift yönlü görev aktivite eğitiminin, denge üzerindeki etkisi konvansiyonel egzersizlerden daha olumlu bir etkisi olmuş (26). İnmeli hastalarda risk faktörlerinin iyi tanımlanması da egzersiz protokolünün belirlenmesine katkı sağlayacaktır.

Literatüre baktığımızda; daha çok çift yönlü görev aktivitesi esnasında denge ve yürüme parametrelerindeki değişiklikleri değerlendiren çalışmalar mevcut. Bizim çalışmamızda çift yönlü görev aktivite eğitimi alan inmeli hastalar tedavi sonrasında fonksiyonel ve yaşam kalitesi parametreleri incelenerek değerlendirildi. Çift yönlü görev egzersizi alan inmeli hastalar ve konvansiyonel egzersiz alan hastalarda iyileşme anlamlı idi ancak iki yöntemin birbirine üstünlüğü saptanmadi.

Örneklem büyüklüğü ve akut/subakut/kronik dönemdeki tüm inmeli hastaların çalışmaya alınması çalışma limitasyonlarıdır. Ayrıca inmeli hastalardaki spontan remisyon diğer pek çok çalışmada olduğunu gibi burda da tedavi etkinliğini değerlendirmeyi güçleştirmektedir.

Sonuç olarak; çalışmamızda çift yönlü görev aktivite eğitiminin inmeli hastalarda etkisini inceledik. Çift yönlü görev aktivite eğitimi inmeli hastalarda fonksiyonel düzey, yaşam kalitesi ve mental duruma olumlu etkisi olup, konvansiyonel tedavilere üstünlüğü yoktur. İnmeli hastalarda nörorehabilitasyonda tercih edilebilir.

Çıkar Çatışması ve Finans Durumu: Çalışmamız bir kurum ve kuruluşça finanse edilmemiştir. Bu çalışmada yazarlar arasında herhangi bir konuda çıkar çatışması bulunmamaktadir.

\section{KAYNAKLAR}

1. Beyazova M, Kutsal YG, Aydın G, Çapacı K, Göğüş F, Gündüz H ve ark. Fiziksel Tip ve Rehabilitasyon 2. Basım, cilt 2, Güneş Tip Kitapevi, Ankara, 2011, s:2761-87

2. Alawieha A, Zhaod J, Feng W. Actors affecting post-stroke motor recovery: Implications on neurotherapy after brain injury. Behav Brain Res. 2018;340:94-101.

3. Frontera WR, Delisa JA, Gans BM, Walsh NE, Robinson LR. Delısa Fiziksel Tip ve Rehabilitasyon İlkeler ve Uygulamalar (çev:Arasıl T, Eskiyurt N), Güneş Tip Kitabevi, Ankara, 2014, s:551-71
4. Silpupadol P, Siu KC, Shumway-Cook A, Woollacott MH. Training of balance under single and dual-task conditions in older adults with balance impairment. Phys Ther. 2006; 86:269-81.

5. Kim HD, Brunt D. The effect of a dual-task on obstacle crossing in healthy elderly and young adults. Arch Phys Med Rehabil. 2007;88:1309-13.

6. Martın IB. Current tanı ve tedavi Fiziksel Tip ve Rehabilitasyon (Çev: Ketenci A, Evcik D, Çetin A, Şendur ÖF), Ema Tip Kitapevi, İstanbul, 2016, s:209-36

7. Debbie Rand; Daniel Gottlieb; Patrice L. (Tamar) Weiss. Recovery of Patients with a Combined Motor and Proprioception Deficit During the First Six Weeks of Post Stroke Rehabilitation. Phys Occup Ther Geriatr. 2001;18(3):69 - 87

8. Tacchino A, Veldkamp R, Coninx K, Brulmans J, Palmaers S, Hämäläinen P, et al. Design, Development, and Testing of an App for Dual-Task Assessment and Training Regarding Cognitive-Motor Interference (CMI-APP) in People With Multiple Sclerosis: Multicenter Pilot Study. JMIR Mhealth Uhealth 2020;8(4):e15344. doi: 10.2196/15344.

9. Batum M, Ak AK, Yılmaz H. The Relationship of Stroke and Sleep- A Review. Journal of Turk Sleep Med. 2017;4:95-103

10. Oğuz H, Dursun E, Dursun N. Tibbı Rehabilitasyon.1. basım, Nobel Tip Kitapevi, İstanbul, 2004, s: 589-617

11. Akın. B, Emiroğlu O. N. Rivermead mobilite indeksi (RM) Türkçe formunun yaşlılarda geçerlilik ve güvenliliği Turk Jour Geriatr. 2007;10(3):124-13

12. Patomella AH, Mälstam E, Eriksson C, Bergström A, Åkesson E, Kottorp A, et al. Primary prevention of stroke: randomised controlled pilot trial protocol on engaging every day activities promoting health. BMJ Open. 2019;9:e031984. doi:10.1136/ bmjopen-2019- 031984

13. Tamam B, Taşdemir N, Tamam Y. İnme sonrası demans: sıklığı ve risk faktörleri Türk Psik Derg. 2008;19(1):46-56

14. Topçu S, Oğuz S. Efficacy and quality of life after stroke. Jour Hum Scien. 2017;14(2):1388-1396.

15. Akdeniz D, Em S, Çağlayan M, Bozkurt M, Oktayoğlu P, Karakoç $M$ ve ark. İnmeli hastalarda uyku kalitesi ve ilişkili faktörlerin değerlendirilmesi Firat Tip Derg. 2015;20(2):86-91

16. Cüngen C, Ertan T, Eker E, Yaşar R, Engin F. Standardize Mini MentalTest'in Türk Toplumunda Hafif Demans Tanısında Geçerlik ve Güvenirliliği. Turk Psik Derg. 2002; 13(4):273-281

17. Ünver E, Alpan ŞC. Ergenlik Öncesi Erkek Çocuklarda Fiziksel Aktivite Düzeyinin 6 Dakika Yürüme Testi İle İlişkisi. Hacet Spor Bil Derg. 2017;28(4):194-204.

18. Park JH. Dual Task Training Effects on Upper Extremity Functions and Performance of Daily Activities of Chronic Stroke Patients. Osong Public Health Res Perspect. 2019;10(1):2-5

19. Pan X. L. Efficacy of early rehabilitation therapy on movement ability of hemiplegic lower extremity in patients with acute cerebrovascular accident. Medicine (Baltimore). 2018;97(2):e9544

20. Yokoyama H, Okazaki K, Imai Dİ, Yamashina Y, Takeda R, Nooshin $\mathrm{N}$, et al. The effect of cognitive-motor dual-task training on cognitive function and plasma amyloid $\beta$ peptide $42 / 40$ ratio in healthy elderly persons: a randomized controlled trial. BMC Geriatr. 2015;15:60.

21. Nascimento C, Ayan C, Lirani-Silva E, Montes L, Cancela J. Physical Exercises and Functional Mobility in Single and Dual-Task in the Elderly: Relation ship with Cognitive Function. Austin Alzheimers J Parkinsons Dis. 2016;3(1):1025.

22. Yang YR, Wang RY, Chen YC, Kao MJ. Dual-Task Exercise Improves Walking Ability in Chronic Stroke: A Randomized Controlled Trial. Arch Phys Med Rehabil. 2007;88:1236-40. 
23. Liu YC, Yang YR, Tsai YA, Wang RY. Cognitive and motor dual task gait training improve dual task gait performance after stroke - A randomized controlled pilot trial . Sci Rep. 2017;7(1):4070.

24. Elhinidi EIM. , Ismaeel MMI, El-Saeed TM. Effect of dual-task training on postural stability in children with infantile hemiparesi, J Phys Ther Sci. 2016;28:875-880

25. Hanneke JR, Van D, Heeren A, Peters MAM, Veerbeek JM, Kwakkel G et al. Effects of Exercise Therapy on Balance Capacity in Chronic Stroke Systematic Review and Meta-Analysis. Stroke. 2016;47:2603-2610.

26. Park MO, Lee SH. Effect of a dual-task program with different cognitive tasks applied to stroke patients: A pilot randomized controlled trial. Neuro Rehab. 2019;44(2):239-249 